\title{
Morfometrik parametrelerin havza hidrolojisi bakımından değerlendirilmesi
}

\author{
Ayten Erol Görür ${ }^{\text {a,* (D), Canan Karadeniz }}{ }^{\text {b }}$
}

\begin{abstract}
Özet: Bir havzanın topoğrafik ve drenaj ağı özellikleri, su kaynaklarının sürdürülebilirliğini sağlamak bakımından ele alınan havza yönetimi planlarında önemli bir yere sahiptir. Havza Yönetimi kapsamında ele alınan çalışma ve uygulamaların ilk aşamalarından birisi havza etütleridir. Morfometrik parametrelerin analizi, arazi etütlerine başlamadan önce alanın hidrolojik, topoğrafik ve jeolojik durumu hakkında bilgilenmemize önemli katkılar sağlamaktadır. Bu çalışmada, Eğirdir Gölü havzasının morfometrik parametreleri Coğrafi Bilgi Sistemi yazılımı yardımıyla sayısal yükseklik modeli verileri kullanılarak sayısal olarak elde edilmiştir. Havza alanı $345850 \mathrm{~km}^{2}$, havzanın çevre uzunluğu ise $375 \mathrm{~km}$ 'dir. Morfometrik değerler; dere sırası (1., 2., 3., 4. , 5. ve 6. derece), dere sayısı (2449 adet), dere uzunluğu $(41742 \mathrm{~km})$, form faktörü $(0.47)$ ve şekil faktörü (2.13), dairesellik oranı (0.31), uzama oranı (0.32), kompaktlık katsayısı $(2.18)$, drenaj yoğunluğu $\left(1.21 \mathrm{~km} / \mathrm{km}^{2}\right)$, dere sıklı̆̆ $\left(0.82\right.$ adet $\left./ \mathrm{km}^{2}\right)$, çatallanma oranı (4.63), drenaj tekstürü (6.54 adet/km) ve infiltrasyon değeri (4.56)'dır. Elde edilen bu değerler, havza hidrolojisi bakımından analiz edilmiştir. Havzanın şekli ve jeolojik yapısı havza hidrolojisi üzerinde etkili olmuştur.

Anahtar kelimeler: Morfometri, Havza, Eğirdir Gölü
\end{abstract}

\section{Evaluation of morphometric parameters for watershed hydrology}

\begin{abstract}
The topographical and drainage network characteristics of a watershed have an important role in the watershed management plans that designed to ensure the sustainability of water resources. One of the first phase of the studies and practices discussed within the scope of watershed management is the surveys. Analysis of morphometric parameters makes a significant contribution to informing about the hydrological status of the area before starting the land surveys. In this study, numerical values of morphometric properties of Lake Eğirdir watershed were obtained by using Geographical Information Systems software. These values are stream order $\left(1^{\text {th }}, 2^{\text {th }}, 3^{\text {th }}, 4^{\text {th }}, 5^{\text {th }}, 6^{\text {th }}\right.$ order $)$, number of streams ( 2449 number) and length of streams $(41742 \mathrm{~km})$, form factor factor (0.47), shape factor (2.13), circularity ratio (0.31), elongation rate (0.32), compactness coefficient (2.18), drainage density $\left(1.21 \mathrm{~km} / \mathrm{km}^{2}\right)$ and stream frequency $\left(0.82\right.$ number $\left./ \mathrm{km}^{2}\right)$, bifurcation rate $(4.63)$, drainage texture $(6.54$ number $/ \mathrm{km}$ ) and infiltration value (4.56). Total area of watershed is 345850 sq. km and watershed perimeter is $375 \mathrm{~km}$. These values were analyzed for watershed hydrology. The shape and geological formation of the watershed were effective on watershed hydrology.

Keywords: Morphometry, Watershed, Lake Eğirdir
\end{abstract}

\section{Giriş}

Artan nüfus karşısında toprak, su ve bitki örtüsü gibi doğal kaynaklar üzerindeki baskılar da artmıştır. Bu durum, bu kaynakların miktar ve kalite bakımından bozulmasına neden olmaktadır. $\mathrm{Bu}$ nedenle doğal kaynakların uygun şekilde planlanması, geliştirilmesi ve korunması gerekmektedir. Morfometri, yeryüzü yüzey şeklinin ve boyutunun ölçülmesini sağlayan matematiksel bir analiz yöntemidir (Agarwal, 1998; Reddy vd., 2002). Bu yöntemle yapılan çalışmalar, esas olarak, akımların çeşitli özelliklerinin ölçülmesini ve değerlendirilmesini içerirler. Nitekim, dünyanın farklı bölgelerinde, birçok nehir havzası ve alt havzasının drenaj durumlarını açıklayan özellikleri morfometrik yöntemlerle incelenmiştir (Horton, 1945; Strahler, 1957, 1964; Krishnamurthy vd., 1996). Bu çalışmalar hem arazi yüzey oluşumu, hem de yüzey drenaj ağlarının oluşum ve davranışını araştırmak için geliştirilmiş sayısal fizyografik yöntemlerdir (Horton, 1945; Strahler,
1957, 1964; Krishnamurthy vd., 1996; Pidwirny, 2006; Melelli vd., 2014). Drenaj ağı parametrelerinin analizi; derelerin çeşitli derecelerde sıralanması, havza alanı, havza çevresi, drenaj kanallarının uzunluğu, drenaj yoğunluğu, drenaj sıklığı, drenaj ağının çatallanma oranı, drenaj tekstürü ve uzama oranı gibi havza özelliklerinin sayısallaştırılmasını (Kumar vd., 2000) kapsamaktadır. Ayrıca, jeomorfolojide yüzey drenaj ağlarının değişimini ve davranışını tanımlamak için de sayısal fizyografik yöntemler geliştirilmiştir (Leopold ve Maddock, 1953; Abrahams, 1984). Bu yöntemlerde, havza şeklinin matematiksel analizi olan morfometrisi ve yer şekillerinin boyutları yer almaktadır (Agarwal, 1998). Morfometrik analiz, havzanın hem doğrusal ve alansal hem de topografik özelliklerinin değerlendirilmesini kapsamaktadır. Bu değerlendirmelerden elde edilen sonuçlar, toprak ve su kaynaklarının korunmasını sağlayan çalışmalarda kolaylık sağlamaktadır. Havza yönetim planlamalarında yer verilmesi gereken bu değerlendirmeler, havza topoğrafyası

\footnotetext{
$凶$ a Isparta Uygulamalı Bilimler Üniversitesi, Orman Fakültesi, Havza Yönetimi Anabilim Dalı, 32260 Isparta

b Isparta Uygulamalı Bilimler Üniversitesi, Fen Bilimleri Enstitüsü, 32260, Isparta

@ * Corresponding author (İletişim yazarı): aytenerol@isparta.edu.tr

$\checkmark \quad$ Received (Geliş tarihi): 31.10 .2018 , Accepted (Kabul tarihi): 18.12.2018
}

Citation (Atıf): Erol Görür, A., Karadeniz, C., 2018. Morfometrik parametrelerin havza hidrolojisi bakımından değerlendirilmesi. Turkish Journal of Forestry, 19(4): 447-454. DOI: $10.18182 / \mathrm{tjf} .476776$ 
ve drenaj ağı özelliklerinin ölçülmesi bakımından yararlıdır. Nitekim havza süreçleri, jeomorfik ve hidrolojik süreçler olarak ele alınırlar. Bu süreçler, arazi yüzeyinin oluşumu ve gelişimi ile ilgili bilgileri de ortaya koymaktadır (Singh, 1992; Dar vd., 2013). Daha da önemlisi, bir havzanın morfometrik analizi yapıldığı takdirde toprak ve su kaynaklarının yönetimi ile ilgili zorlukların ve havza yönetim planlarının taşıyacağı risklerin azaltılabileceği (Martins ve Gadiga, 2015) kabul edilmektedir. Bu nedenle, morfometrik analizin havza ile ilgili klavuz niteliğinde bir çalışma ve havza yönetimi için en uygun yöntem olduğu da (Reddy vd., 2004; Latief vd., 2015; Farhan vd., 2016) ifade edilmektedir.

Bu çalışmada, göller bölgesindeki, en büyük sulama ve içme suyu kaynaklarından biri olan Eğirdir Gölü havzasının morfometrik özellikleri belirlenmiştir. Bu amaçla Coğrafi Bilgi Sistemleri (CBS)'nden yararlanılmış ve her bir parametre için sayısal değerler elde edilmiştir. Hesaplanan morfometrik özellikler, Eğirdir Gölü havzasının hidrolojik özelliklerini değerlendirmek amacıyla kullanılmıştır.

\section{Materyal ve yöntem}

\section{1. Çalışma alanı ve özellikleri}

Eğirdir Gölü havzası, Isparta ili sınırları içerisinde yer almaktadır. Isparta ilinin kuzey-kuzeydoğu sınırını oluşturan göl havzası; 5 ilçe merkezi, 17 belde ve 59 köyden oluşan toplam 81 yerleşim birimini kapsamaktadır. Çalışma alanının, 48436 ha'1 Eğirdir Gölü'nün yüzey alanı olup, toplam alanı 345850 ha'dır. Havza alanı, $37^{\circ} 45^{\prime}-38^{\circ} 30^{\prime}$ kuzey enlemleri ve $30^{\circ} 15^{\prime}-31^{\circ} 30^{\prime}$ doğu boylamları arasında yer almaktadır (Şekil 1). Havzanın çevre uzunluğu 374,7 $\mathrm{km}$, deniz seviyesinden ortalama yüksekliği $930 \mathrm{~m}$ ve araştırma alanının en yüksek noktası 2750 m' dir. Eğirdir Gölü havzası, İç Anadolu Bölgesi karasal iklimi ile Akdeniz Bölgesi 1lıman iklimi arasındaki geçiş kuşağı içerisindedir. Bölge yağış ve sıcaklık özellikleri nedeniyle karasal bölge iklimine daha yakındır (Başyiğit, 2002). Toplam havza alanının \%75.08'i \%0-30'luk eğim grubunda (düz, eğimli ve kısmen dik) ve bunun da \%45.98'inin düz ve kuzey bakılarda yer aldığı görülmektedir. Aynı şekilde, toplam havza alanının \%24.92'sinin \%30-80 olan eğim grubunda (çok dik) olduğu ve bunun da \%35.31'inin ağırlıklı olarak güney bakıda (Çizelge 1) yer aldığı görülmektedir.

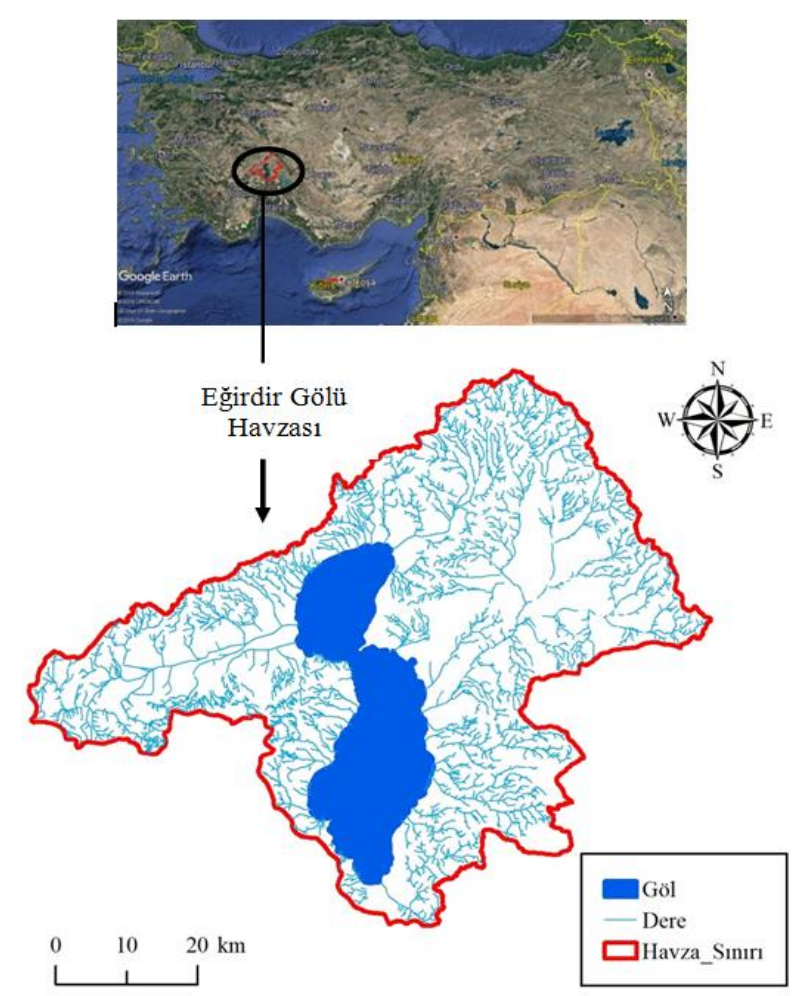

Şekil 1. Eğirdir Gölü havzasının coğrafi konumu

Havza alanının \% 25.19'luk kısmı 915-1000 m yükselti aralığında olup, gölün alanı bu kısımda kalmaktadır. \% 51. 27'lik kısmı ise 1000-1500 m yükselti aralığında olup, yerleşim yerleri ve tarım arazilerinden oluşmaktadır. \% 23.43'lük kısmı 1500-2600 m yükselti aralığındaki alanlar orman ve meyve bahçelerinden oluşmaktadır. \% 0.11 'i ise 2600-2700 m yükselti aralığındadır. Bu alanlar, sarp ve dik kayalıklardan oluşmaktadır. Toplam alanının $54.71 \mathrm{~km}^{2}$.si göl alanıdır. Havzanın \%41.44'ü, düz ve düze yakın eğim (\%0-10 eğim) sınıfındaki arazilerden oluşmaktadır. Bu alan göl ve çevresindeki yerleşim yerleri ve tarım alanlarından oluşmaktadır. Toplam alanın \%33.54' ü hafif ve orta derecede ve kalan \%24.92'lik kısmı ise eğimin dik ve sarp olduğu alanlardan (Çizelge 1) oluşmaktadır.

Araştırma alanı yıllık ortalama yağışın $564.3 \mathrm{~mm}$, yıl içindeki en fazla yağışın Ağustos $(86.5 \mathrm{~mm})$, en az yağışın Aralık (12.1 mm) aylarında, en yüksek yıllık sicaklık ortalaması ise 42.3 ile Temmuz ayındadır (Anonim, 2018).

Çizelge 1. Eğirdir Gölü havzasının eğim ve bakı dağılımı

\begin{tabular}{|c|c|c|c|c|c|c|}
\hline Dere sirası & Eğim sınıfı (\%) & Alan (Ha) & Alan (\%) & Bak1 sinıfi & Alan (Ha) & Alan (\%) \\
\hline 1 & $0-5$ & 107932 & 31.21 & Düz & 70873 & 20.49 \\
\hline 2 & $5-10$ & 35348 & 10.23 & Kuzey & 31004 & 8.96 \\
\hline 3 & $10-15$ & 32957 & 9.54 & Kuzey doğu & 28007 & 8.10 \\
\hline 4 & $15-30$ & 83354 & 24.10 & Doğu & 29144 & 8.43 \\
\hline 5 & $30-50$ & 61963 & 17.90 & Güney doğu & 42063 & 12.16 \\
\hline 6 & $50-80$ & 22077 & 6.38 & Güney & 41811 & 12.09 \\
\hline 7 & $>80$ & 2219 & 0.64 & Güney batı & 38239 & 11.06 \\
\hline & \multirow[t]{3}{*}{ Toplam } & \multirow[t]{3}{*}{345850} & \multirow[t]{3}{*}{100} & Bat1 & 31944 & 9.24 \\
\hline & & & & Kuzey bat1 & 32766 & 9.47 \\
\hline & & & & Toplam & 345850 & 100 \\
\hline
\end{tabular}


Havza alanının doğal bitki örtüsü kurak iklimlere adapte olmuş otsu bitkiler, çalı-orman karışımı doğal örtüler, yüksek alanlarda çam türleri, maki ve meralardır. Orman örtüsü ise meşe türleri ve ardıçlardan oluşmaktadır. Makilikler ve bozulmuş orman örtüsü olarak boz ardiç (Juniperus exelsa Bieb.) ve pırnal meşesi (Quercus aucheri Jaub.) alanda görülen egemen türlerdir. Kuru tarım alanlarında baklagil tarımı yapılmakta, sulanan alanlarda ise yoğun elma tarımı yapılmakta, yağ gülü ve bazı sebze türleri yetiştirilmektedir (Başyiğit, 2002).

Havza ve çevresinde, mevcut bitki türlerini belirlemek amacıyla yürütülen bazı bilimsel çalışmalarda; Kızıldağ'da (Şarkikaraağaç) 776, Aksu ilçesinde 658, Davraz dağında 415 adet bitki türü tespit edilmiştir. Havzada bulunan Sedir (Cedrus libani A. Richard), Ardıç (Juniperus communis L.), Kasnak Meşesi, Toros Göknarı (Abies cilicica Carr.) ve bazı Meşe türleri orman örtüsünü oluşturmaktadır (Erik ve Mutlu, 1997). Havza alanı; alüviyal, tuzlu alkali aluviyal ve hidromorfik alüviyal, kolüviyal, kahverengi orman ve kireçsiz kahverengi orman, kestane rengi, kırmızı Akdeniz ve kırmızımsı kahverengi Akdeniz ve nehir taşkını topraklardan ve çıplak kayalıklardan oluşmaktadır. Göl havzasının batı kısmı üst kratese flişlerinden, güney doğusu Ofiolitli mesozoiklerden oluşurken, kuzey batı yamaçları lokal olarak dağılmış tüf ve eosen fliş formundaki anakayadan oluşmaktadır (Başyiğit, 2002).

\subsection{Morfometrik analiz ve değerlendirilen parametreler}

Havzaların morfometrik özelliklerinin sayısal analizi, toprak ve su kaynaklarının korunarak kullanılması ilkesinin önemli önceliklerinden birisidir. Bu yöntem, havzaların önemli bir yönü olan drenaj sisteminin de sayısal olarak tanımlanmasını sağlar (Strahler, 1957; Strahler, 1964; Nag ve Chakraborty, 2003). Böylece, sistem daha kolay anlaşılmakta ve sistemin değişik etkilere karşı vereceği tepkiler de en uygun şekilde analiz edilebilmektedir. Bu analizlerin yapılması, havzaların topografik ve hidrolojik süreçleri arasındaki ilişkilerini etkileyen faktörlerin doğru olarak değerlendirilmesine yardımcı olmaktadır (Nag ve Chakraborty, 2003; Erol ve İlhan, 2011).

Eğirdir Gölü havzası 37 adet 1:25.000' lik topografik paftadan oluşmaktadır. $\mathrm{Bu}$ paftalar, Harita Genel Komutanlığı'ndan sayısal formatta (vektör) temin edilmiş ve ARCGIS 10.2 yazılımı ile coğrafi veri tabanına kaydedilerek düzenlenmiştir. Sayısal arazi modeli oluşturmak amacıyla CBS yazılımının ilgili modülleri kullanılmış ve sayısal yükseklik modeli üretilmiştir. Çalışmada havzanın morfometrik parametreleri, 1:25.000'lik topografik haritalar ve DEM (Sayısal Yükseklik Modeli) verileri kullanılarak üretilmiştir. Dere katmanı içinde (derenin ismi, dere sınıfı vb.) öz nitelik bilgileri girilerek topolojisi kurulmuştur. Dere katmanı ve sayısal yükseklik modeli kullanılarak alt havzaların sınırları oluşturulmuştur. Böylece, konumsal analizlerin yapabileceği veri tabanı elde edilmiştir (Çizelge 2).

Sayısal yükseklik modeli ve coğrafi veri tabanındaki eşyükselti, bakı, eğim, havza alanı dere uzunluğu ve sırası gibi katmanlardan yararlanılarak Eğirdir Gölü havzasının morfometrik parametrelerinin sayısal değerleri elde edilmiştir. Bunun için basit eşitlikler kullanılmıştır (Çizelge 2). Bu parametreler dere sirası, sayısı ve uzunluğu, form faktörü ve şekil faktörü, dairesellik oran1, uzama oran1, kompaktlık katsayısı, drenaj yoğunluğu ve dere sıklığı, çatallanma oranı, drenaj tekstürü ve infiltrasyon değeridir. $\mathrm{Bu}$ değerler yardımıyla, havzanın jeomorfolojik ve hidrolojik özelliklerini anlamak ve akış durumunu değerlendirmek mümkün olmuştur.

Çizelge 2. Eğirdir Gölü havzasının morfometrik parametreleri ve sayısal değerleri

\begin{tabular}{|c|c|c|c|}
\hline Morfometrik Paremetre & Formül & Referans & Sonuç \\
\hline Havza alanı & & & $345850 \mathrm{~km}^{2}$ \\
\hline Havza çevresi & & & $375 \mathrm{~km}$ \\
\hline \multirow{7}{*}{ Dere sirası ve sayısı } & Hiyerarşik düzenleme & Strahler, 1964 & 1. derece 1849 \\
\hline & & & 2. derece 456 \\
\hline & & & 3. derece 111 \\
\hline & & & 4. derece 25 \\
\hline & & & 5. derece 7 \\
\hline & & & 6. derece 1 \\
\hline & & & Toplam 2449 dere \\
\hline Dere Uzunluğu & $\mathrm{L}_{\mathrm{u}}$ & Horton, 1945 & $41742 \mathrm{~km}$ \\
\hline Form Faktörü $\left(\mathrm{R}_{\mathrm{f}}\right)$ & $\mathrm{R}_{\mathrm{f}}=\mathrm{A} / \mathrm{L}_{\mathrm{b}}^{2}$ & Horton, 1945 & 0.47 \\
\hline Şekil Faktörü $\left(\mathrm{R}_{\mathrm{s}}\right)$ & $\mathrm{R}_{\mathrm{s}}=\mathrm{P}_{\mathrm{u}} / \mathrm{P}_{\mathrm{c}}$ & Sameena vd., 2009 & 2.13 \\
\hline Dairesellik Oranı $\left(\mathrm{R}_{\mathrm{c}}\right)$ & $\mathrm{R}_{\mathrm{c}}=4 \pi * \mathrm{~A} / \mathrm{P}^{2}$ & Strahler, 1964 & 0.31 \\
\hline Uzama Oranı $\left(\mathrm{R}_{\mathrm{e}}\right)$ & $\mathrm{R}_{\mathrm{e}}=\left(2 / \mathrm{L}_{\mathrm{b}}\right) *(\mathrm{~A} / \pi)^{0,5}$ & Strahler, 1964 & 0.32 \\
\hline Kompaktlık Katsayısı (Cc) & $\mathrm{Cc}=0,2821 \mathrm{P} / \mathrm{A}^{0,5}$ & Sreedevi vd., 2013 & 2.18 \\
\hline Çatallanma Oranı $\left(\mathrm{R}_{\mathrm{b}}\right)$ & $\mathrm{R}_{\mathrm{b}}=\mathrm{N}_{\mathrm{u}} / \mathrm{N}_{(\mathrm{u}+1)}$ & Sreedevi, 2013 & 4.63 \\
\hline Drenaj yoğunluğu & $\mathrm{D}=\mathrm{L}_{\mathrm{u}} / \mathrm{A}$ & Horton, 1932 & $1.21 \mathrm{~km} / \mathrm{km}^{2}$ \\
\hline Dere siklığg & $\mathrm{F}_{\mathrm{s}}=\mathrm{N}_{\mathrm{u}} / \mathrm{A}$ & Horton, 1932 & $0.82 \mathrm{adet} / \mathrm{km}^{2}$ \\
\hline Drenaj tekstürü & $\mathrm{R}_{\mathrm{t}}=\mathrm{N}_{\mathrm{u}} / \mathrm{P}$ & Horton, 1945 & $6.54 \mathrm{adet} / \mathrm{km}$ \\
\hline Infiltrasyon değeri & $\mathrm{D} * \mathrm{Fs}$ & Ali ve Khan, 2013 & 4.56 \\
\hline
\end{tabular}

$\mathrm{R}_{\mathrm{f}}=$ form faktörü, $\mathrm{A}=$ havzanın alanı $\left(\mathrm{km}^{2}\right), \mathrm{L}_{\mathrm{b}}=$ havzanın uzunluğu, $\mathrm{R}_{\mathrm{s}}=$ şekil faktörü, $\mathrm{P}_{\mathrm{u}}=$ havzanın alanıyla aynı alana sahip çemberin çevresi,

$\mathrm{P}_{\mathrm{c}}=$ havzanın çevresi, $\mathrm{R}_{\mathrm{c}}=$ dairesellik oranı, $\mathrm{P}=$ havzanın çevresi, $\mathrm{R}_{\mathrm{e}}=$ uzama oranı, $\mathrm{Cc}=$ kompaktlık katsayısı, $\mathrm{P}=$ havzanın çevresi, $\mathrm{R}_{\mathrm{b}}=$ çatallanma oranı, $\mathrm{N}_{\mathrm{u}}=$ toplam dere sayısı, $\mathrm{N}_{(\mathrm{u}+1)}=$ Bir sonraki üst dere sayısı, $\mathrm{D}=$ Drenaj yoğunluğu 


\section{Bulgular ve tartışma}

Bölge için önemli bir su kaynağı olan Eğirdir Gölü havzasına ait morfometrik özellikler, havzanın topografik ve drenaj ağı özelliklerini değerlendirmek amaciyla kullanılmıştır. Eğirdir Gölü’nün büyük kısmı güney bakıda yer almaktadır. Bu kısımda eğim yönleri göle doğru olmakla birlikte göl havzasının kuzeydoğusunda farklı eğim yönlerinin içinde girişlerin bulunduğu geniş alanlar yer almaktadır. Kısacası, Eğirdir Gölü havzasının bakısı; göl alanının da içinde yer aldığı düz alan ile havzanın çevresindeki güney, güney batı, güney doğu ve kuzey batı yönleridir.

Sayısallaştırılan parametrelerden dere sırası, dere sayısı, dere uzunluğu, çatallanma oranı değerleri, havzanın doğrusal boyutunu ve drenaj sisteminin topografyayla ilişkisini göstermektedir (Ali ve Khan, 2013; Rai vd., 2018). Dere sıklığı, drenaj tekstürü, dairesellik oranı gibi parametreler ise havzanın alansal boyutunu gösteren değerlerdir (Ali ve Khan, 2013). Havzaların drenaj dağılım tipi, çeşitli etkenlere bağlı kalarak değişikliklere uğramakta ve belirli nitelikler kazanmaktadır (Gregory ve Walling, 1976). Eğirdir Gölü havzası, ülkemizde yayın olarak bulunan dendritic drenaj tipine sahiptir.

\subsection{Dere strası, sayısı ve uzunluğu}

Dere sırası ve sayısı akarsu derelerindeki hiyerarşik sıralamayı ifade eder. $\mathrm{Bu}$ parametreleri sayısallaştırmak amacıyla, CBS yardımıyla, havzanın drenaj kolları belirlenmiş ve dere sırası numaraları verildikten sonra belirlenen her bir derece için dere sayıları elde edilmiştir.

Eğirdir Gölü havzasında dere sayıları 1. derece için 1849 adet (\%75.50), 2. derece için 456 adet (\%18.62), 3. derece için 111 adet (\%4.53), 4. derece için 25 adet (\%1.02), 5. derece için 7 adet $(\% 0.29)$ ve 6 . derece için 1 adet (\%0.04)'tür. Havza alanı içindeki oranıyla en büyük paya sahip olan dere sırası 1, en düşük paya sahip olan dereler ise 6. derecedeki derelerdir (Çizelge 2). Morfometrik analizin ilk belirlenen parametreleri olan dere sayısı ve sirasında izlenen temel kural, toplam dere sirası artarken toplam dere sayısının azalmasıdır. Benzer şekilde, dere kollarının toplam uzunluğu, dere sırası arttıkça azalmakta ve birinci dereceden derelerde maksimum olmaktadır (Horton, 1945; Strahler, 1964; Farhan vd., 2017; Rai vd., 2018). Eğirdir Gölü havzasında 6.dereceye kadar yükselen toplam 2449 adet kuru ve sulu dere bulunmakta ve toplam uzunlukları 41742 km'yi bulmaktadır. Dere sayısı ve sırasındaki değişim büyük ölçüde havza alanının jeolojik yapısı ve morfolojik özellikleri ile ilgili (Farhan vd., 2016; Kuntamalla vd., 2018) olup, havza büyüklüğüne ilişkin bilgi vermektedir. Benzer şekilde, alanın fizyografik ve yapısal özellikleri de dere sırası ve sayısına etki eden önemli faktörlerdir (Rai vd., 2018). Dere sırası artarken, dere sıklığında (0.82) bir azalma olmakta ve maksimum frekans 1 . derecedeki dere sirasının olduğu durumu teşkil etmektedir (Rai vd., 2018). Derelerin sıra derecesi artıkça havza şeklinin yuvarlak geometrik bir şekle yakın olduğu da (Farhan vd., 2016) belirtilmektedir. Derelerdeki değişim; akımın yüksek rakımlardan oluşması, anakaya özelliklerindeki değişimlerden ve orta derecedeki dik yamaçlardan kaynaklandığını (Strahler, 1964) göstermektedir.
Dere uzunluğu, havza hidrolojisinin değerlendirilmesinde kullanılan önemli bir parametredir. $\mathrm{Bu}$ değer, havzadaki kayaç oluşumlarının permeabilitesi hakkında genel bir fikir verir. Daha da önemlisi, art arda gelen dere siralarının olması durumu, drenaj kolları altındaki kaya yüzeylerinin hidrolojik özelliklerinde önemli değişikliklerin olduğunu (Rai vd., 2018) göstermektedir. Eğirdir Gölü havzasının ardışı dere durumunda olması, dere sayısının artığını ve dere uzunluğu oranının artan bir eğilimde olduğunu göstermektedir. Dere uzunluğu oranının bir dere sırasından diğerine değişimi ise jeolojik gelişimin son gençlik evresinde olduğu anlamına gelmektedir (Singh vd., 2014; Rai vd., 2014). Küçük dere uzunlukları, daha büyük eğime sahip alanları ve daha ince tekstür özelliklerini ortaya koymaktadır Dere uzunluğunun artması ise genellikle yamaç eğiminin çok dik olmadığına işaret etmektedir.

\subsection{Form faktörü ve şekil faktörü}

Havza şekli, yağışla toplanan suyun pik debilerini ve taşkın gibi hidrografik özelliklerini değerlendirmek için kullanılmaktadır (Özhan, 2004). Bunun için bazı eşitlikler geliştirilmiştir. Bunlardan form faktörü; havza alanının havza uzunluğunun karesine bölünerek elde edilmekte, şekil faktörü ise havza uzunluğunun karesinin havza alanına oranlanmasıyla bulunmaktadır. Her iki parametre de havza alanı ile uzunluğu arasındaki ilişkiyi göstermektedir (Çizelge 2).

Havza şekli, suyun konsantrasyon zamanını etkileyen önemli faktörlerden biridir. Form faktörünün düşük değerler (0'a yaklaşan) aldığ 1 havzalar, dar ve uzun havzalar olarak nitelendirilmektedir. $\mathrm{Bu}$ tip havzalarda suyun toplanma süresi daha uzun olacağı için daha düşük akımlar oluşmaktadır (Horton, 1932). Yüksek form faktör değerine (1'e yaklaşan) sahip havzalar ise daha kısa veya orta uzunlukta, yani daireselliğe yaklaşan havzalar olarak nitelendirilir (Horton, 1932; Kutukcu vd., 2015). Şekli dairesele yakın olan havzalarda, toplanma zamanı kısa olacağından, kısa sürede yüksek akımlar oluşacaktır (Bishop ve Victoria, 2001; Kutukcu vd., 2015; Veeranna vd., 2017). Eğirdir Gölü havzasında form faktörü 0.47 'dir. Bu değerin 1'den küçük çıkması havza uzunluğunun, havza genişliğinden büyük olduğunu göstermektedir. Şekil faktörü ise 2.13 'tür. Şekil faktörünün 1'den büyük bulunması da havzanın uzunlamasına bir şekli olduğunu göstermektedir. Yapılan bir araştırmada (Bishop ve Victoria, 2001), form faktörü 0.42 olan bir havzanın daha az uzunlamasına bir şeklinin olduğu ifade edilmektedir. $\mathrm{Bu}$ değerlendirme de şekli dairesele yakın olan bu havzada suyun toplanma zamanı daha kısa olacağından, kısa sürede yüksek akımlar oluşacaktır. $\mathrm{Bu}$ değerler gösteriyor ki, havzaya yağışla düşen suyun toplanma süresi daha uzun olacağından ani taşkın oluşma ihtimali de daha düşük olacaktır.

\subsection{Dairesellik oranı}

Havzaların şeklini saptamada kullanılan bir diğer parametre dairesellik oranıdır. Havza alanının havza çevresine eşit çevreye sahip bir dairenin alanına oranı ile hesaplanan (Özhan, 2004) bu değer araştırma havzası için 0.31 bulunmuştur (Çizelge 2). Jeolojik yapı bakımından homojenlik gösteren küçük havzalarda bu oranın 0.6-0.7 arasında değiştiği, buna karşılık, heterojen bir jeolojik 
yapıya sahip olan havzalarda bu oranın daha uzun bir havza şeklini temsil ettiği ve 0.4-0.5 arasında değişebildiği (Hızal, 1984; Özhan, 2004) ifade edilmektedir. Eğirdir Gölü havzasının uzunluğu geniş̧liğinden büyük olduğundan, jeolojik olarak, heterojen bir yapıya sahip ve daireselden uzaklaşan bir şeklinin olduğu söylenebilir.

\subsection{Uzama oranı}

Alanı havza alanına eşit bir dairenin çapının, havza uzunluğuna oranı ile bulunan bu değer 1'e eşit veya 1'den küçük olmaktadır (Özhan, 2004). Havza şeklinin dar veya geniş olduğunu gösteren bir parametredir. Çok değişik iklim ve jeolojik özellikler gösteren bölgelerde bu oranın 0.6-1.0 arasında değiştiği, 1 olmasının ise alçak topoğrafyayı temsil ettiği, ancak 0.6-0.8 arasındaki değerlerin genellikle dik ve sarp bir topografik durumu gösterdikleri (Balc1 ve Özyuvacı, 1988) ifade edilmektedir. Benzer şekilde, uzama oranı 0.43-0.83 arasında olan havzaların yüksek topografik koşullara sahip oldukları ve dik eğimli oldukları (Panhalkar vd., 2012) belirtilmektedir. Eğirdir Gölü havzası için bu değer 0.32'dir (Çizelge 2). Araştırma havzasının çok dik ve sarp olmamakla birlikte, dağlık ve topografik açıdan dar bir havza olduğu söylenebilir.

\subsection{Kompaktlık katsayısı}

Havza çevresinin, havza alanına sahip bir dairenin çevresine oranı ile bulunan bu değer 1'e eşit veya 1'den büyüktür (Özhan, 2004). Araştırma havzası için bu değer 2.18 bulunmuştur (Çizelge 2). Havza şekli ile ilgili bir diğer parametre olan kompaktlık katsayısının değeri büyüdükçe havzanın şekli daireden uzaklaşmaktadır (Özhan, 2004; Çokoyoğlu, 2008). Nitekim Eğirdir Gölü havzasının şekli de daireden uzaklaşan, uzunlamasına bir durum göstermektedir.

Havza şeklini belirlemek amacıyla geliştirilen dere sırası, dere sayısı, dere uzunluğu, form faktörü, şekil faktörü, dairesellik oranı, uzama oranı ve kompaktlık katsayısı eşitlikleri, Eğirdir Gölü havzasının dairesellikten uzaklaşan bir şeklinin olduğunu göstermektedir. Havza şekli, sediment birikimi ve taşkın olaylarını değerlendirmek bakımından önemli bir parametredir.

\section{6. Çatallanma oranı}

Çatallanma oranı, bir havzadaki toplam dere sayısının bir üst derenin toplam sayısına oranı (Strahler, 1964) olup, herhangi bir sıradaki dere sayısının bir sonraki sıradaki dere sayısına oranını ifade etmek için kullanılır (Rai vd., 2018). Havzadaki her bir dere sayısı alındıktan sonra bu değerlerin ortalaması alınarak havzanın çatallanma oranı değeri bulunur.

$\mathrm{Bu}$ çalışmada, elde edilen çatallanma oranı değeri ile ortalama çatallanma oranı değeri ifade edilmektedir. Genel olarak, elde edilen çatallanma oranı değerleri; sabit bir sayı üzerinden değerlendirilmez, sonuçlar daha çok farklı havzaların değerleri karşılaştııılarak önem kazanır. Bu değer, Eğirdir Gölü Havzasında 4.63'tür (Çizelge 2). Bir havzadaki çatallanma oranı değeri düşük ise o havzadaki akımlara ait hidrograflar daha keskin ve yüksek, bu değer yüksek ise hidrograf daha düşük ve devamlı olabilmektedir (Strahler, 1964). Çatallanma oranı, 3-5 arasında bir değer aldığında havza jeolojisinin daha homojen bir yapı gösterdiği belirtilmektedir (Chow, 1964; Verstappen, 1983; Ritter vd., 2002). Ancak, Eğirdir Gölü havzasında derelerin çatallanma oranının 1., 2. ve 3. dereceden derelerin yüksek değerler göstermesi nedeniyle homojen bir jeolojik yapıya sahip olduğu söylenemez. Nitekim, 1. ve 2. dereceden dere sırası bulunan havzaların çatallanma oranının, daha yüksek derecedeki (4., 5. ve 6. derece) derelerin çatallanma oranından daha yüksek belirtilirken, bu durumun aynı zamanda erozyonun bir göstergesi olduğu (Verstappen, 1983; Sreedevi vd., 2013; Magesh ve Chandrasekar, 2014) ifade edilmektedir. $\mathrm{Bu}$ parametre, taşkınların tespiti ve değerlendirmesinde akış hidrografının rolünü öne çıkarmaktadır (Chorley, 1969). Genel olarak, havzanın çatallanma oranı düşük olduğunda hidrograf keskin bir pik akış üretir. Bu durumda, alanın düşük bir havza verimine sahip olduğu, ancak çatallanma oranı yüksek olduğunda yayvan bir pik eğrisi verebildiği ve taşkın riskinin daha düşük olduğu (Agarwal, 1998) belirtilmektedir. Öte yandan, diğer bazı çalışmalarda (Nag, 1998; Strahler,1964; Chandrashekar vd., 2015; Kabite ve Gessesse, 2018) havzanın çatallanma oranının 5'den küçük olması üç şekilde nitelendirilmiştir. Bunlar; 1) havzanın dirençli kayaçlara sahiptir, 2) dereler büyük ölçüde 1., 2.ve 3.dereceden dereceden derelerden oluşmaktadır, ve 3) homojen bir jeolojisi olduğu için erozyondan daha az etkilenir. Ancak, araştırmaya konu olan havzanın çatallanma oranı nispeten 5'den küçük olmasına rağmen jeolojik yapı bakımından heterojenlik göstermektedir. $\mathrm{Bu}$ durumda, Eğirdir Gölü havzasının erozyondan etkilenme düzeyinin çok düşük olmadığı söylenebilir. Nitekim dairesellik oranı da havzanın heterojen bir jeolojik yapıya sahip olduğunu göstermektedir.

\subsection{Drenaj yoğunluğu}

Drenaj yoğunluğu, havza analizinin temel unsurlarından birisidir olup, diğer morfometrik unsurları ifade etmek için kullanılan önemli bir parametredir (Rai vd., 2018). Bu parametre, havzanın birim alanındaki dere uzunluğu olup (Horton, 1932, 1945; Strahler, 1952, Melton, 1957; Farhan vd., 2016), drenaj analizinin temel unsurlarından birini oluşturur (Rai vd., 2018). Diğer bir anlatımla, havzada bulunan bütün derelerin toplam uzunluğunun havzanın alanına bölünmesiyle elde edilmekte ve havzanın birim alanındaki $\left(\mathrm{km}^{2}\right)$ dere uzunluğu $(\mathrm{km})$ olarak ifade edilmektedir. Drenaj yoğunluğunun düşük olması, jeolojik yapının dayanaklı kayaçlardan oluştuğunu ve derelerin genç oluşumlu bir özellik taşıdıklarını göstermektedir (Özşahin, 2008). Araştırma havzasının drenaj yoğunluğu değeri 1.21 $\mathrm{km} / \mathrm{km}^{2}$ bulunmuştur (Çizelge 2). Bu değerin düşük olması, jeolojik yapının dayanaklı kayaçlardan oluştuğunu ve derelerin genç oluşumlu bir özellik taşıdıklarını göstermektedir (Özşahin, 2008). Genel olarak, küçük drenaj yoğunluğu değerleri topoğrafyanın alçak olduğu ve arazinin sık bir vejetasyonla kaplı bulunduğu havzalarda ve alt toprağın çok dayanıklı veya geçirgen olduğu bölgelerde görülmektedir. Buna karşılık büyük drenaj yoğunluğu değerleri, çoğunlukla, dağlık ve vejetasyonun seyrek olduğu ve alt toprağın da dayanıksız veya geçirgenliğinin az olduğu yerlerde görülmektedir (Hızal, 1984). Drenaj yoğunluğu, havzanın dereler tarafından parçalanmasının bir ölçüsü olarak da değerlendirildiğinden yüzeysel akışı kontrol eden faktörlerin (geçirgenlik, bitki örtüsünün seyreklik veya sıklığı, topografya ve iklim) etkisiyle havzadaki sediment ve su üretimini etkiler (Melton, 1957; Mačka, 2001; Reddy vd., 
2004; Farhan vd., 2016; Rai vd., 2018), yaptıkları çalışmada $1.081 \mathrm{~km} / \mathrm{km}^{2}$ olan drenaj yoğunluğunun 1lımlı bir değer olduğunu ifade etmişlerdir. Drenaj yoğunluğunun düşük ya da ortalama bir değer aldığı alanlarda, bitki örtüsünün sık olduğu ve alt toprak yapısının geçirgen olduğu ifade edilmektedir (Nag, 1998; Panhalkar vd., 2012). Eğim ve nispeten yükseklik, drenaj yoğunluğunu kontrol eden morfolojik durumlardır (Rai vd., 2018). Arazi yapısının daha az engebeli olduğu yerlerde drenaj yoğunluğunun düşük olacağı (Strahler, 1964), yüksek olduğu yerlerde ise daha yüksek olacağ havzasının drenaj yoğunluğu değeri 1.21'dir. Buna göre, Eğirdir Gölü havzasının drenaj yoğunluğunun ortalama bir değer olduğu, bitki örtüsü bakımından çok sık olmasa da alt toprak yapısının ortalama bir geçirgenlikte olduğu söylenebilir.

\subsection{Dere sıklı̆̆l}

Dere sıklığı, havza içindeki dere sayısının (adet) havza alanına $\left(\mathrm{km}^{2}\right)$ bölünmesiyle elde edilir (Horton, 1932, 1945). Bu değer, maksimum yağış anındaki dere sıklığı değerlerini vermektedir. Yüksek dere sıklı̆̆ı değerleri geçirgen olmayan zemin özelliklerini, seyrek bitki örtüsü ve yüksek topografik yapı özellikleri gösterirken, düşük sıklık değerleri geçirgen olan arazi yapısı özellikleri ve alçak topografya özelliklerini ortaya koymaktadır (Reddy vd., 2004). Havzanın dere sıklığı, dere yoğunluğu ile ilişkili olup, dere popülasyonundaki artışı göstermektedir. Genellikle havzanın arazi yapısının kayaç özellikleri tarafından kontrol edilir ve akış ağının yapısını belirler (Rai vd., 2018). Çoğunlukla, drenaj yoğunluğu ve dere sıklığ arasında doğru orantı olduğu kabul edilmektedir (Melton,1958). Bu parametre üzerinde iklim, zeminin litolojik özellikleri, jeomorfolojik özellikler, bitki örtüsü, süre ve insan gibi çeşitli etmenlerin rolleri vardır (Hoşgören, 2001; Özdemir, 2011). Benzer bir çalışmada (Peltier,1962), ortalama eğim değerlerine sahip bölgelerden yarı kurak olanında dere sıklık değeri fazla, kurak bölgelerde çok az ve nemli bölgelerde orta değerlerde bulunmuştur.

Çalışma havzasının dere sıklığı 0.82 olarak belirlenmiştir (Çizelge 2). Bu değer düşük bir dere sıklığı olarak kabul edilebilir. Düşük değerler ise geçirgen olan arazi yapısı özellikleri ve alçak topografya özelliklerini ortaya koymaktadır.

\subsection{Drenaj tekstürü}

Drenaj tekstürü; arazinin kayaç yapısı, infiltrasyon kapasitesi ve arazi şekli hakkında fikir vermektedir (Ali ve Khan, 2013; Rai vd., 2018). Horton (1945)'a göre drenaj tekstürü, havza çevresinin her bir $\mathrm{km}^{2}$ sinde yer alan tüm derecelerdeki toplam dere kollarının sayısıdır (Horton, 1945). 2'den daha az olan drenaj tekstürü değeri çok iri taneli, 2-4 arasındaki kaba tekstürlü, 4-6 arası orta tekstürlü, 6-8 arası ince ve 8 ' den büyük olanlar çok ince tekstürü göstermektedir (Smith, 1950; Ali ve Khan, 2013; Rai vd., 2018). Rai vd., (2018)' nin çalışmalarında drenaj tekstürü, 21.44 bulunmuş ve çok ince drenaj tekstürü kategorisinde gösterilmiştir. Eğirdir Gölü havzasının drenaj tekstürü değeri 6.54 bulunmuştur (Çizelge 2). Bu değerin, kaba tekstürle ince tekstüre daha yakın bir değer olduğu ve havza topraklarının nispeten geçirgen olduğu söylenebilir.

\subsection{Infiltrasyon dĕgeri}

İnfiltrasyon değeri, drenaj yoğunluğu ve dere sıklığının bir ürünüdür (Ali ve Khan, 2013). Araştırma alanın infiltrasyon sayısı değeri 4.56 bulunmuştur (Çizelge 2). İnfiltrasyon sayıs1 18.28 olan bir havzada infiltrasyonun düşük, yüzeysel akışın yüksek olduğu ifade edilmektedir (Ali ve Khan, 2013). Eğirdir Gölü havzası için bulunan değer infiltrasyonun (sızma) yeterli olduğu göstermektedir.

\section{Sonuc}

Morfometrik parametreler, havzalardaki toprak ve su kaynaklarının yönetimini mikro düzeyde değerlendirmek için kullanılan matematiksel verilerdir. Eğirdir Gölü Havzasını hidrolojik olarak değerlendirmek gerektiğinde, havza şekli ve drenaj sisteminin durumu hakkında bir ön çalışma yapılabilir. Havza şeklini gösteren parametreler, havzaya yağışla düşen suyun akış hızı ve toplanma zamanı hakkında değerlendirme yapılabileceğini göstermektedir. Araştırma havzasının şekli, dairesellikten uzaklaşan ve nispeten uzunlamasına bir yap1 göstermektedir. $\mathrm{Bu}$ durumda, havzada ani taşkın oluşma ihtimalinin düşük olacağı söylenebilir. Havzanın drenaj durumu, dere sisteminden alınan toprak örneklerine ait veriler olmasa dahi alanın jeolojik yapısı, toprak özellikleri ve bitki örtüsü durumu hakkında bilgi verebilmektedir. Bu nedenle, havza topraklarının erozyondan etkilenip etkilenemeyeceği ve akış hidrografının davranışıyla ilgili yorum yapılabileceği söylenebilir. Eğirdir Gölü havzasının şekli, havza üzerine düşen yağış sularının toplanma zamanı ve akışa geçme hızının düşük olacağını, drenaj durumu ise havzanın çok dik ve sarp bir topoğrafik yapıya sahip olmamakla birlikte, jeolojik yapısı nedeniyle alt toprağın dayanıklı olmayan bir yapıda olduğunu göstermektedir. Bu iki durum hidrolojik bakımdan değerlendirildiğinde, Eğirdir Gölü Havzası topraklarının erozyon riski taşıdığ yağış sularını havza çıkışına ulaştırma hızı ve suyun toplanma zamanı bakımından gösterdiği davranış, bu riskin en az düzeyde olacağını göstermektedir. Bununla birlikte, bitki örtüsü durumu korunduğu takdirde erozyon nedeniyle oluşacak sediment birikiminin göl havzasına vereceği zarar en aza indirilebilir.

Tüm bu sonuçlar göstermektedir ki, havza etüdleri kapsamında morfometrik parametrelerin analiz edilmesi hidrolojik değerlendirmelere önemli katkılar sağlayacaktır.

\section{Açıklama}

$\mathrm{Bu}$ çalışma, "Morfometrik Parametreler ve Havza Hidrolojisi Üzerindeki Etkileri" başlıklı yüksek lisans tezinden üretilmiştir.

\section{Kaynaklar}

Abrahams, A.D., 1984. Channel networks: A geomorphological perspective. Water Resources, 20: 161-168.

Agarwal, C.S., 1998. Study of Drainage Pattern through aerial data in Navgarh area of Varanasi district, U.P. Journal Indian Society of Remote Sensing, 26: 169-175.

Ali, S.A., Khan, N., 2013. Evaluation of morphometric parameters; A remote sensing and GIS based approach. Open Journal of Modern Hydrology, 3: 20-27. 
Anonim, 2018. İllerimize ait genel istatistik verileri. Meteoroloji Genel Müdürlüğü, https://www.mgm.gov.tr/veridegerlendirme/il-ve-ilceleristatistik.aspx, Erişim: 09.10.2018.

Balcı, N., Özyuvacı, N., 1988. Havza Amenajmanı II. İ.Ü. Orman Fakültesi, Yüksek Lisans Ders Notları, İstanbul.

Başyiğit, L., 2002. Eğirdir Gölü havzasında erozyon riskinin saptanması üzerine araştırmalar. Doktora Tezi, Çukurova Üniversitesi, Fen Bilimleri Enstitüsü, Adana.

Bishop, V., Victoria, R., 2001. Water Resources: Process and Management. Series of Landmark Geography, Harpercollins Pub Ltd, 2nd edition (May 31, 2001), London.

Chandrashekar, H., Lokesh, V.K., Sameena,M., Roopa, J., Ranganna, G., 2015. GIS-based morphometric analysis of two reservoir catchments of Arkavati River, Ramanagaram District, Karnataka. International Conference on Water Resources, Coastal and Ocean Engineering (ICWCOE 2015), Aquatic Procedia, 4: 1345-1353.

Chorley, R.J., 1969. Introduction to Fluvial Processes. Methuen and Co. Limited, London.

Chow, V.T., 1964. Handbook of Applied Hydrology. Mc Graw Hill Book Company, New York.

Çokoyoğlu, S., 2008. Alibey ve Kağıthane havzalarında arazi kullanımı ve sorunlarının 50 yıllık değişimi. Yüksek Lisans Tezi, İstanbul Üniversitesi, Fen Bilimleri Enstitüsü, Orman Mühendisliği Anabilim Dalı, İstanbul.

Dar, R.A., Chandra, R., Romshoo, S.A., 2013. Morphotectonic and lithostratigraphic analysis of intermontane Karewa basin of Kashmir Himalayas. India, Journal of Mountain Science, 10 (1): 731-741.

Erik, S., Mutlu, B., 1997. Kızıldağ (Isparta) Milli Parkı florası. TÜBİTAK (Proje No: TBAG- 1320), Ankara.

Erol, A., İlhan, Ş., 2011. Aksu havzası envanteri. SDÜ Orman Fakültesi Dergisi, 12: 77-83.

Farhan, Y., Anaba, O., Salim, A., 2016. Morphometric analysis and flash floods assessment for drainage basins of the Ras En Nawb Area, South Jordan using GIS. Journal of Geoscience and Environment Protection, 4: 933.

Farhan, Y., 2017. Morphometric assessment of Wadi Wala Watershed, Southern Jordan using ASTER (DEM) and GIS. Journal of Geographic Information System, 9: 158190, DOI:10.4236/jgis.2017.92011.

Gregory, K.J., Walling, D.E., 1976. Drainage basin form and process. A geomorphological approach printed in Great Britain by Flectcher and Son Ltd., Norwich.

Hızal, A., 1984. Havza fotoğrafları yorumlamasının havza amenajmanı (Ova Deresi Havzası, Kocaeli) çalışmalarında uygulanma olanaklarının araştırılması. İ.Ü. Yayın No: 3144, O.F. Yayın no: 341, İstanbul.

Horton, R.E., 1932. Drainage basin characteristics. Trans. American Geophysical Union 13: 350-361, DOI:10.1029/TR013i001p00350.

Horton, R.E., 1945. Erosional development of stream and their drainage basin. Hydrogeological approach to quantitative morphology, Bulleting of Geological Society of America, 56: 275-361.

Hoşgören, M.Y., 2001. Hidrografya'nın Ana Çizgileri I: Yeraltısuları-Kaynaklar-Akarsular. Çantay Kitabevi, 4. Bask1, İstanbul.
Kabite, G., Gessesse, B., 2018. Hydro-geomorphological characterization of Dhidhessa River Basin, Ethiopia. International Soil and Water Conservation Research, 6 (2): 175-183.

Krishnamurthy, J., Srinivas, G., Jayaram, V., Chandrasekhar, M.G., 1996. Influence of rock types and influence in development of drainage network in typical hardrock terrain. ITC. 3 (4): 252-259.

Kumar, R., Lohani, A.K., Nema, R.K., Singh, R.D., 2000. Evaluation of Geomorphological characteristics of catchment using GIS. GIS India, 9 (3): 13-17.

Kuntamalla, S., Gugulothu, S., Nalla, M., Raj Saxena, P., 2018. Drainage basin analysis through GIS: A Case study of Lakhnapur Reservoir Watershed in Rangareddy District, Telangana State, India. International Journal of Engineering, Science and Mathematics, 7 (3): 9-17 (Special Issue), DOI:10.13140/RG.2.2.22464.84484.

Kutukcu, A., Kaya, S., Kabdasli, S., Gazioglu, C., 2015. Nehir havzalarının morfolojik karakteristiklerinin CBS destekli nümerik modeller kullanılarak analizi. TUFUAB VIII. Teknik Sempozyumu, 21-23 Mayis 2015, Konya, s.58-70.

Latief, S. U., Naqvi, H. R., Alam, A., Amin, A., 2015. Morphometric analysis of east liddar watershed, northwestern himalayas, scientific society of advanced research and social change 2 (1), https://www.researchgate.net/publication/279195476, Erișim: 06.12.2018.

Leopold, L.B., Maddock, T., 1953. The hydraulic geometry of stream channels and some physiographic implications, USGS Professional paper, 252: 1-57.

Mačka, Z., 2001. Determination of texture of topography from large scale contour maps. Geografski vestnik, 73 (2): 53-62.

Magesh, N.S., Chandrasekar, N., 2014. GIS model-based morphometric evaluation of Tamiraparani sub-basin, Tirunelveli district, Tamil Nadu, India. Arab J. Geosci, 7: 131-141.

Martins, A. K., Gadiga, B. L., 2015. Hydrological and morphometric analysis of upper Yedzaram Catchment of Mubi in Adamawa State, Nigeria. Using Geographic Information System (GIS), World Environment 5(2): 6369.

Melelli, L., Liucci, L., Vergari, F., Ciccacci, S., Monte, M.D., 2014. Fluvial drainage networks: the fractal approach as an improvement of quantitative geomorphic analyses. Geophysical Research Abstracts, 16: EGU2014-12452.

Melton, M.A., 1957. An analysis of the relation among elements of climate, surface properties and geomorphology, Tch. Rep. No. 11, Department of Geology, Columbia University, New York.

Nag, S.K., 1998. Morphometric analysis using remote sensing techniques in the chaka sub-basin, purulia district, West Bengal. Journal of the Indian Society of Remote Sensing, 26(1-2):69-76, DOI: 10.1007/BF03007341.

Nag, S.K., Chakraborty, S., 2003. Influence of rock types and structures in the development of drainage network in hard rock area. Journal of the Indian Society of Remote Sensing, 31 (1): 25-35. 
Özdemir, H., 2011. Havza morfometrisi ve taşkınlar, Fiziki Coğrafya Araştırmaları: Sistematik ve bölgesel. Ekinci, D., Havza Morfometrisi ve Taşkınlar içinde, Türk Coğrafya Kurumu Yayınları, İstanbul, s. 507-526.

Özhan, S., 2004. Havza Amenajmanı. İ.Ü. Orman Fakültesi Havza Amenajmanı Anabilim Dalı, İ.Ü. Rektörlük Yayın No: 4510, Orman Fakültesi Yayın No: 481, İstanbul.

Özsahin, E., 2008. Keçidere (Gönen Çayı'nın bir kolu) havzasının hidrografik özelliklerine sayısal yaklaşım. Mustafa Kemal Üniversitesi Sosyal Bilimler Enstitüsü Dergisi, 5 (10): 301-317.

Panhalkar, S.S., Mali, S.P., Pawar, C.T, 2012. Morphometric analysis and watershed development prioritization of Hiranyakeshi basin in Maharashtra, India. International Journal of Environmental Sciences, 3 (1): 525534, DOI:10.6088/ijes.2012030131052.

Peltier, L.C., 1962, Area Sampling for Terrain Analysis. Professional Geographer, 14: 2428.

Pidwirny, M., 2006. The drainage basin concept. Fundamentals of Physical Geography, 2nd Edition.

Rai, P.K., Mohan, K., Mishra, S., Ahmad, A., Mishra,V.N., 2014. A GIS based approach in drainage morphometric analysis of Kanhar river basin, India. Applied Water Science. DOI: 10.1007 /s13201-014-0238-y.

Rai, P.K., Chandel, R.S., Mishra, V.N, Singh, P., 2018. Hydrological inferences through morphometric analysis of lower Kosi river basin of India for water resource management based on remote sensing data. Applied Water Science, 8:15, DOI:10.1007/s13201-018-0660-7.

Reddy, G.P. O., Maji A.K., Gajbhiye K.S., 2002. GIS for morphometric analysis of drainage basins. GIS India, 4: 9-14.

Reddy, G.P.O., Maji, A.K., Gajbhiye, K.S., 2004. Drainage morphometry and its influence on landform characteristics in basaltic terrain, central India-a remote sensing and GIS approach. International Journal of Applied Earth Observation and Geoinformation,6:1-16.

Ritter, D., Kochel, R., Miller, J., 2002. Process Geomorphology. Mc Graw-Hill, New York.

Sameena, M., Krishnamurthy.J., Jayaraman.V. Ranganna,G., 2009. Evaluation of drainage networks developed in hard rock terrain. Geocarto International, 1-24, DOI:10.1080/10106040802601029.
Singh, P., Gupta, A., Singh, M., 2014. Hydrological inferences from watershed analysis for water resource management using remote sensing and GIS techniques. Egyptian Journal of Remote Sensing and Space Science, 17: 111-121.

Singh, S., 1992. Quantitative geomorphology of the drainage basin. In: Chouhan, T.S., Joshi, K.N., (Eds.), Readings on Remote Sensing Applications, Scientific Publishers, Jodhpur, India, s. 121-129.

Smith, K.G., 1950. Standards for grading textures of erosional topography. American Journal of Science, 248:655-668.

Sreedevi, P.D., Sreekanth, P.D., Khan, H.H., Ahmed, S., 2013. Drainage morphometry and its influence on hydrology in a semi-arid region: using SRTM data and GIS. Environmental Earth Sciences, 70(2):839-848.

Strahler, A.N., 1952. Hypsometric (area-altitude) analysis of erosional topography. Bulletin of the Geological Society of Amerika, 63(11):1117-1142.

Strahler, A.N., 1957. Quantitative analysis of American Geomorphology Transactions. American Geophysical Union, 38: 913-920.

Strahler, A.N., 1964. Quantitative geomorphology of drainage basins and channel networks. In: V. T. Chow (Ed.) New York: McGraw Hill, Handbook of Applied Hydrology, pp. 4-76.

Veeranna, J., Gouthami, K., Yadav, P. B.,Mallikarjuna, V.R., 2017. Calculating linear and areal and relief aspect parameters using Geo-Spatial Techniques (ArcGIS 10.2 and SWAT model) for Akkeru River Basin Warangal. International Journal of Current Microbiology and Applied Sciences, 6 (10): 1803-1809.

Verstappen, H., 1983. Applied Geomorphology: Geomorphological Surveys for Environmental Development. Elsevier, New York. 